Article

\title{
Studies Regarding As(V) Adsorption from Underground Water by Fe-XAD8-DEHPA Impregnated Resin. Equilibrium Sorption and Fixed-Bed Column Tests
}

\author{
Mihaela Ciopec, Adina Negrea, Lavinia Lupa *, Corneliu M. Davidescu and Petru Negrea \\ Faculty of Industrial Chemistry and Environmental Engineering Blvd., \\ "Politehnica" University of Timisoara, Vasile Parvan No. 6, Timisoara 300223, Romania \\ * Author to whom correspondence should be addressed; E-Mail: lavinia.lupa@upt.ro; \\ Tel.: +4-025-640-4192.
}

External Editor: Derek J. McPhee

Received: 11 July 2014; in revised form: 12 September 2014 / Accepted: 18 September 2014 / Published: 9 October 2014

\begin{abstract}
The characteristics of arsenic adsorption onto Fe-XAD8-DEHPA resin were studied on the laboratory scale using aqueous solutions and natural underground waters. Amberlite XAD8 resin was impregnated with di(2-ethylhexyl) phosphoric acid (DEHPA) via the dry method of impregnation. Fe(III) ions were loaded onto the impregnated resin by exploiting the high affinity of arsenic towards iron. The studies were conducted by both in contact and continuous modes. Kinetics data revealed that the removal of arsenic by Fe-XAD8-DEHPA resin is a pseudo-second-order reaction. The equilibrium data were modelled with Freundlich Langmuir and Dubinin Radushkevich (D-R) isotherms and it was found that the Freundlich model give the poorest correlation coefficient. The maximum adsorption capacity obtained from the Langmuir isotherm is $22.6 \mu \mathrm{g} \mathrm{As}(\mathrm{V}) / \mathrm{g}$ of Fe-XAD8-DEHPA resin. The mean free energy of adsorption was found in this study to be $7.2 \mathrm{~kJ} / \mathrm{mol}$ and the $\Delta G^{\circ}$ value negative $(-9.2 \mathrm{~kJ} / \mathrm{mol})$. This indicates that the sorption process is exothermal, spontaneous and physical in nature. The studied Fe-XAD8-DEHPA resin showed excellent arsenic removal performance by sorption, both from synthetic solution and the natural water sample, and could be regenerated simply by using aqueous $\mathrm{NaOH}$ or $\mathrm{HCl}$ solutions.
\end{abstract}

Keywords: arsenic removal; Fe-XAD8-DEHPA; underground water; adsorption isotherm; kinetics; column study 


\section{Introduction}

Because in developing countries underground waters represent the main source of drinking water, their contamination with arsenic is a problem which must be solved [1-3]. It is well known that because of its toxicity the presence of arsenic in drinking water above the maximum admitted level has a negative impact on human health [1-8]. In order to reduce its adverse health effects it is necessary to minimize the pollution of underground water with arsenic content or to find some effective methods for their remediation [3]. The valences and inorganic species of arsenic depend on the redox conditions and the $\mathrm{pH}$ of the underground waters. In an aqueous solution of $\mathrm{As}(\mathrm{V})$ there are four species: $\mathrm{H}_{3} \mathrm{AsO}_{4}$, $\mathrm{H}_{2} \mathrm{AsO}_{4}{ }^{-}, \mathrm{HAsO}_{4}{ }^{2-}, \mathrm{AsO}_{4}{ }^{3-}$ that predominate at $\mathrm{pH}$ values between 6 and 9. In the same mode in aqueous solutions at $\mathrm{pH}$ values below 9 they exist the $\mathrm{As}(\mathrm{III})$ species: $\mathrm{H}_{3} \mathrm{AsO}_{3}, \mathrm{H}_{2} \mathrm{AsO}_{3}{ }^{-}, \mathrm{HAsO}_{3}{ }^{2-}$, $\mathrm{AsO}_{3}[4-6,9,10]$. The conventional methods used for the arsenic removal from aqueous solutions are precipitation, coagulation and filtration, reverse osmosis, ion exchange and adsorption. Of the above methods, adsorption is the most promising one as it is economical and highly efficient [1-12]. In the last years solvent impregnated resins (SIR) were used for the recovery and selective separation of metal ions from aqueous solutions with good results [13-22]. In order to improve the adsorption properties of the SIRs four method of impregnation with an organic extractant of the polymeric support were developed. These are: the dry, wet, modifier addition and dynamic column methods [13,16,22-24]. In the present study, the dry method of impregnation was used to impregnate an Amberlite XAD8 resin with di(2-ethylhexyl) phosphoric acid DEHPA in order to obtain an efficient adsorbent for the removal of $\mathrm{As}(\mathrm{V})$ from aqueous solutions [22]. We focused on this resin because in our previous studies the Amberlite XAD7 resin displayed good adsorption properties in the process of arsenic removal from aqueous solutions [18]. The advantages of the use as solid support of the Amberlite XAD series are represented by the possibilities of obtaining spherical beads of suitable size. Other researchers used these resins for the arsenic removal, but in other more expensive functionalization systems [20,21]. Due to the shape of these solid supports they are easy to separate from the solutions and also easy to regenerate, avoiding in this way the drawbacks of the adsorption method. On the other hand the purpose of our research was to obtain an adsorbent which could be efficiently used in the process of arsenic removal from aqueous solutions having concentrations under $100 \mu \mathrm{g} / \mathrm{L}$. These concentrations were the most common found in the underground waters from the west area of Romania and east area of Hungary [25,26]. Awual and co-workers underlined the importance of the preparation of an adsorbent intended to remove arsenic from waters containing low concentrations. They also demonstrated that the metal-loaded ligand exchangers show rapid, selective and great efficiency in the process of trace arsenic removal from aqueous solutions [27-31]. For this reason, in this paper, in order to prepare an efficient adsorbent for the purification of water with trace levels of arsenic, the XAD8-DEHPA impregnated resin was loaded with Fe(III) ions. We used the iron ions for the metal loading of the impregnated resin due to the high affinity of arsenic towards iron [3,4,7-11,24,32]. By using as adsorbent material, in the process of arsenic removal from aqueous solutions, a resin loaded with a polyvalent metal ion, combines the known advantages of the resin such as excellent hydraulic properties and mechanic strength along with the excellent selectivity offered by the loaded metal ion [33]. Even if the metal ion content (weight \%) of the loaded resin is much less than the metal oxide, the resulting adsorbent presents a higher efficiency due to its mechanical integrity and its 
possibility to be used for several cycles [34]. Taking into account these considerations the purposed adsorbent material is in agreement with the Life Cycle Approach, underlining the sustainability of arsenic removal through adsorption [35]. The objective of this study was to investigate the adsorption characteristic of the Fe-XAD8-DEHPA resin for As(V) removal in aqueous solutions by performing equilibrium sorption tests and fixed-bed column tests.

\section{Results and Discussion}

\subsection{Evaluation of the Adsorbent Preparation Process}

The extractant content of the XAD8-DEHPA was found to be $0.28 \mathrm{~g}$ DEHPA for each gram of SIR as determined by titration using $0.1 \mathrm{M} \mathrm{NaOH}$. The experimental data regarding the dependence of the $\mathrm{Fe}(\mathrm{III})$ ion uptake versus the initial concentration on $\mathrm{Fe}$ (III) ions in the loading process of iron onto XAD8-DEHPA resin are presented in Figure 1.

Figure 1. Dependence of the Fe(III) ions uptake versus the initial concentration of Fe(III) $\mathrm{pH}=3, t=24 \mathrm{~h}, m=0.1 \mathrm{~g}, V=25 \mathrm{~mL}$.

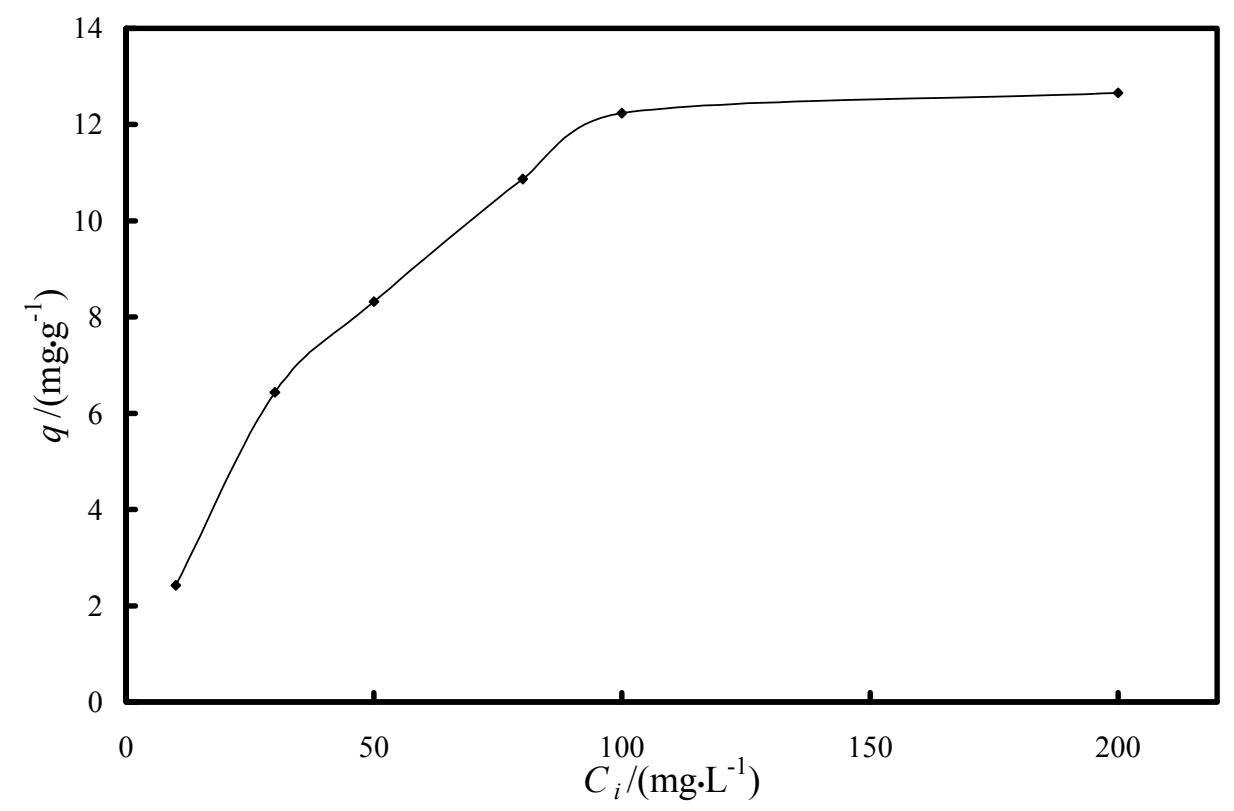

The experimental data shows the increase of the Fe(III) ions uptake as the initial concentration of $\mathrm{Fe}(\mathrm{III})$ ions in solution increases. Above $100 \mathrm{mg} / \mathrm{L}$ initial Fe(III) concentration, there is no significant increase of the Fe(III) ions loaded onto the XAD8-DEHPA. Therefore it was considered that for the loading of the XAD8-DEHPA resin, using a S:L ratio of $0.1: 25$, the concentration of the Fe(III) ions in the aqueous solutions should not exceed $100 \mathrm{mg} / \mathrm{L}$. In this way the loading of the highest quantity of iron ions onto the impregnated resin is obtained, which will lead to a higher adsorption of $\mathrm{As}(\mathrm{V})$ ions from the aqueous solution, due to the fact that the $\mathrm{Fe}(\mathrm{III})$ ions are responsible for the arsenic removal because of its affinity for this pollutant [3,4,7-11,24,32].

The IR spectrum of Fe-XAD8-DEHPA (Figure 2) presents the characteristic bands of XAD8 resin and also illustrated the fact that the resin was impregnated with the studied solvent and loaded with the $\mathrm{Fe}(\mathrm{III})$ ions. The peak at $1390 \mathrm{~cm}^{-1}$ was assigned to the $\mathrm{C}-\mathrm{H}$ deformation vibration of $\mathrm{CH}_{3}$; the 
absorption band at $1734 \mathrm{~cm}^{-1}$ corresponds to a $\mathrm{C}=\mathrm{O}$ stretching vibration and the band at $2970 \mathrm{~cm}^{-1}$ was attributed to the $\mathrm{C}-\mathrm{H}$ stretching vibration of $\mathrm{CH}_{3}$. The impregnated status of the XAD8 resin by DEHPA extractant is manifested in the appearance of the adsorption band at $1235 \mathrm{~cm}^{-1}$, which is the $\mathrm{P}=\mathrm{O}$ stretching band. $\mathrm{P}-\mathrm{CH}_{2}$ stretching is observed at $1477 \mathrm{~cm}^{-1}$; the $\mathrm{O}-\mathrm{H}$ bending band was found at $1690 \mathrm{~cm}^{-1}$ and the band assigned to $\mathrm{P}-\mathrm{OH}$ is observed at $2340 \mathrm{~cm}^{-1}$. The iron loading of the XAD8-DEHPA resin is demonstrated by the peaks at 1037 and $2890 \mathrm{~cm}^{-1}$ which belong to the Fe-OH stretching band.

Figure 2. IR spectrum of a Fe-XAD8-DEHPA sample.

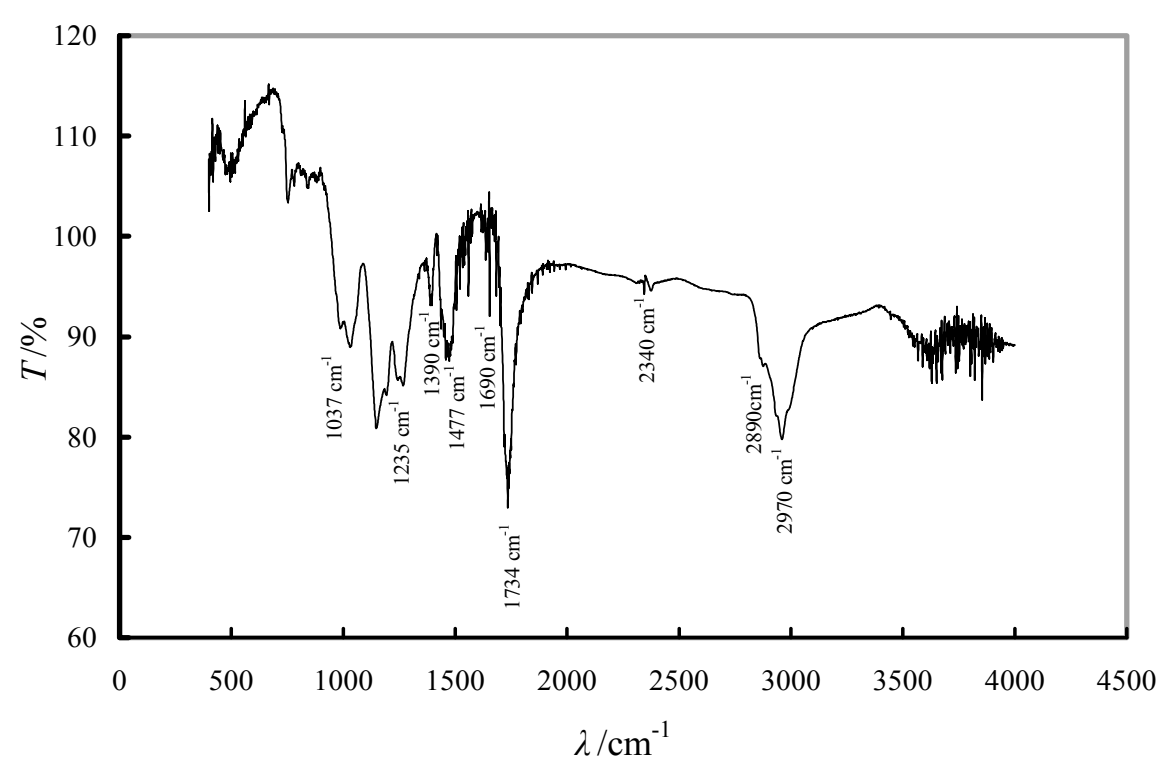

The impregnation of the resin with DEHPA and the loading of the impregnated resin with Fe(III) ions is also demonstrated by the EDX spectra, where characteristic peaks of phosphorous ions arising from the DEHPA solvent and iron were identified (Figure 3).

Figure 3. EDX spectrum of Fe-XAD8-DEHPA sample.

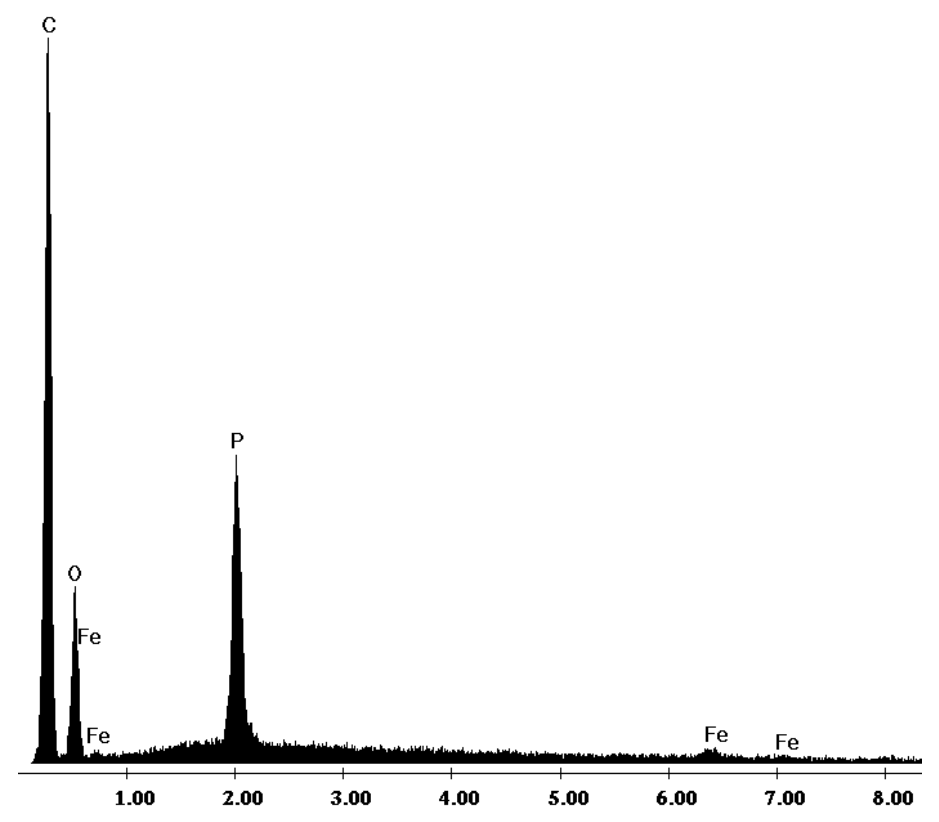




\subsection{Sorption Equilibrium Tests}

\subsubsection{Study of the Kinetics of Adsorption}

In order to determine the time when the equilibrium between the arsenate and the impregnated resin is reached kinetic studies were performed. The effect of contact time on the equilibrium adsorption capacity of Fe-XAD8-DEHPA during the removal process of $\mathrm{As}(\mathrm{V})$ from aqueous solution at room temperature is presented in Figure 4. According to this data, saturation was reached after $24 \mathrm{~h}$ contact time. At an initial $100 \mathrm{ppb} \mathrm{As}(\mathrm{V})$ concentration value, the equilibrium adsorption capacity was determined to be $\sim 13 \mu \mathrm{g} \mathrm{As}(\mathrm{V}) / \mathrm{g}$ of impregnated resin.

Figure 4. Effect of contact time on the As(V) adsorption capacity of Fe-XAD8-DEHPA $\mathrm{pH}=9 \pm 0.1 ; T=298 \pm 1 \mathrm{~K} ; C_{0}=100 \mu \mathrm{g} / \mathrm{L} ; m=0.1 \pm 0.0001 \mathrm{~g} ; V=25 \pm 0.1 \mathrm{~mL}$.

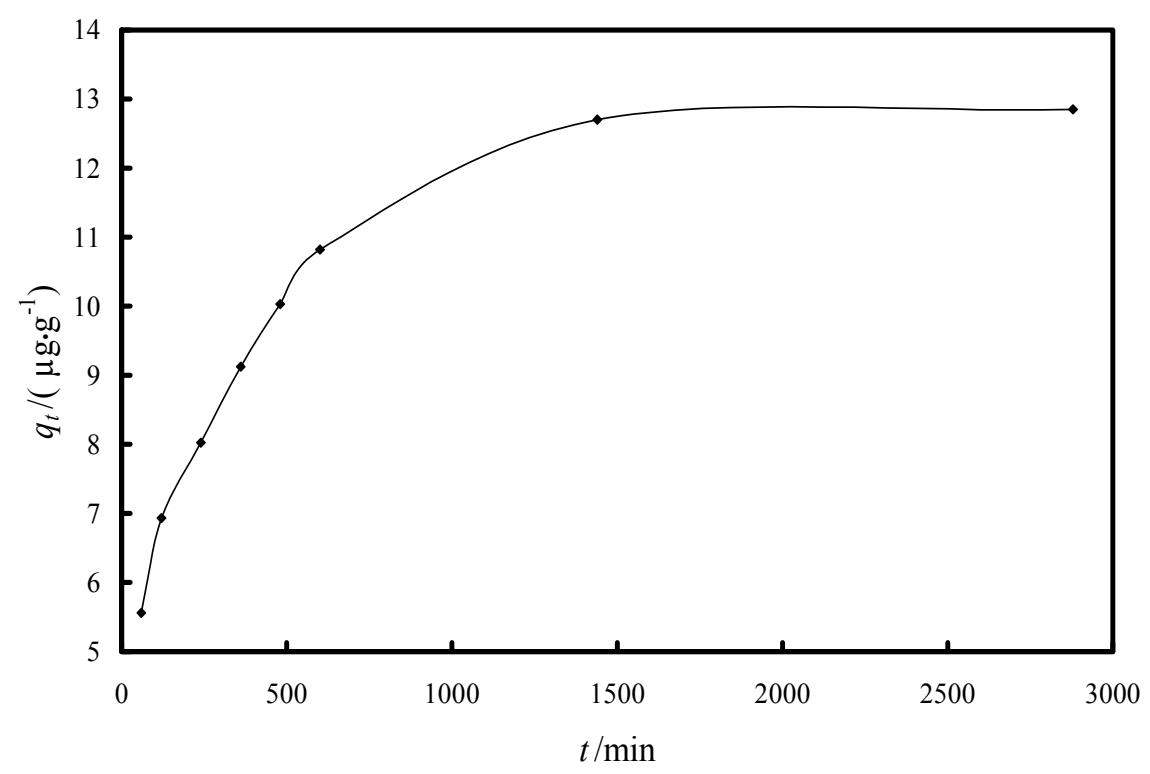

In order to investigate the arsenic adsorption mechanism onto the Fe-XAD8-DEHPA resin, three kinetic models, namely (i) pseudo-first-order equation of Lagergren based on solid capacity; (ii) pseudo-second-order reaction model of Ho and Mckay based on the solid phase sorption; and (iii) intra-particle diffusion model were tested. Descriptions of the integral form of the models are given in the following. The pseudo-first-order kinetic model is defined by the Equation $[14,36]$ :

$$
\ln \left(q_{e}-q_{t}\right)=\ln q_{t}-k_{1} \cdot t
$$

where $q_{e}$ and $q_{t}$ are the amount of the $\mathrm{As}(\mathrm{V})$ adsorbed onto the Fe-XAD8-DEHPA ( $\left.\mu \mathrm{g} / \mathrm{g}\right)$ at equilibrium and after time $t$, respectively. $t$ is the contact time (min), $k_{1}$ is the specific sorption rate constant $\left(\mathrm{min}^{-1}\right)$. The values of the adsorption rate constant $\left(k_{1}\right)$ were determined from the $\ln \left(q_{e}-q_{t}\right)$ in terms of $t$ (Figure 5). 
Figure 5. Linear model of the pseudo-first-order reaction kinetics of $A s(V)$ adsorption onto Fe-XAD8-DEHPA resin.

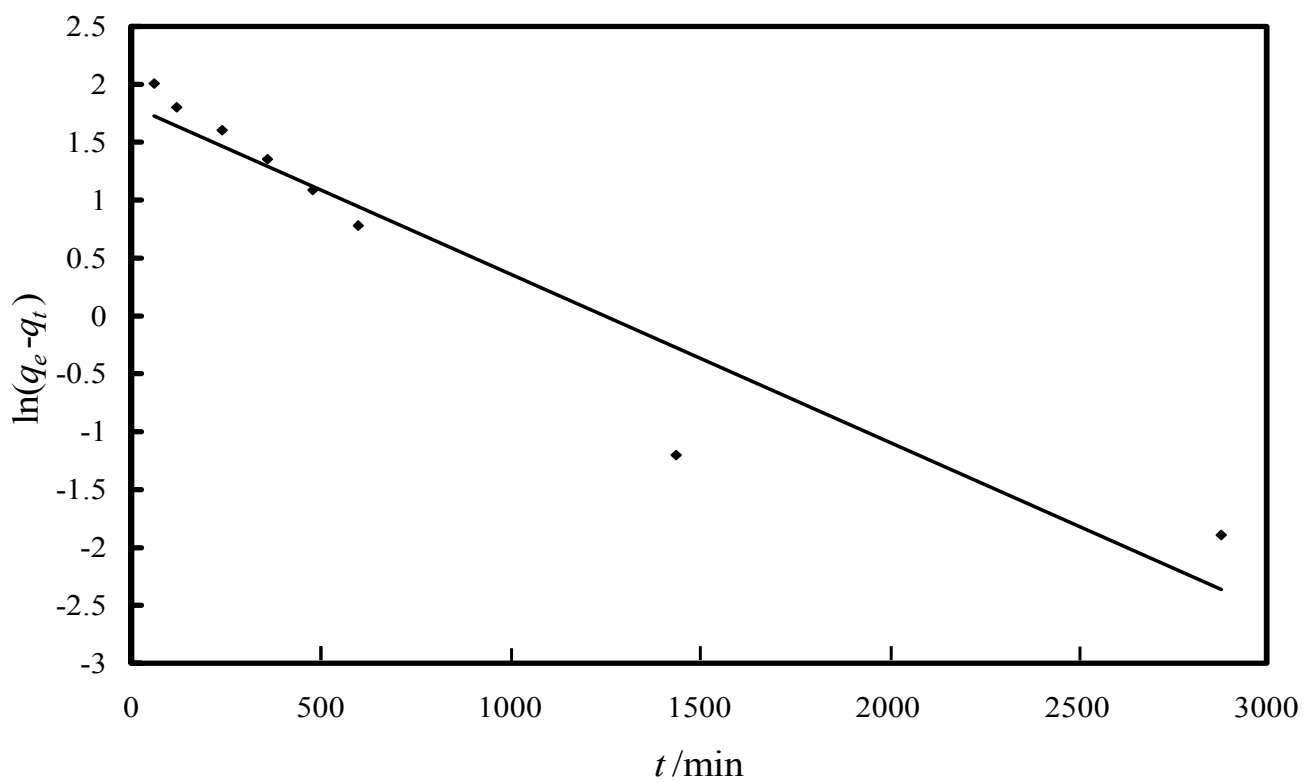

The linear form of the pseudo-second order model is defined by [2,37]:

$$
\frac{t}{q_{t}}=\frac{1}{k_{2} \cdot q_{e}^{2}}+\frac{t}{q_{e}}
$$

where $q_{e}$ and $q_{t}$ are the amount of the $\mathrm{As}(\mathrm{V})$ adsorbed onto the studied material $\left(\mu \mathrm{g} \cdot \mathrm{g}^{-1}\right)$ at equilibrium and at time $t$, respectively. $t$ is the contact time $(\mathrm{min}), k_{2}$ is the pseudo-second-order adsorption rate constant $\left(\mathrm{g} \cdot \mu \mathrm{g}^{-1} \cdot \mathrm{min}^{-1}\right)$. The value $q_{e}$ and $k_{2}$ are determined from the slope and intercept of $\left(t \cdot q_{t}^{-1}\right)$ versus $t$ (Figure 6). In Equation (2), the expression $k_{2} \cdot q_{e}{ }^{2}$ in the intercept term describes the initial sorption rate $h /\left(\mu \mathrm{g} \cdot(\mathrm{g} \cdot \mathrm{min})^{-1}\right)$ as $\mathrm{t} \rightarrow 0$.

Figure 6. Linear model of the pseudo-second-order reaction kinetics of $\mathrm{As}(\mathrm{V})$ adsorption onto Fe-XAD8-DEHPA resin.

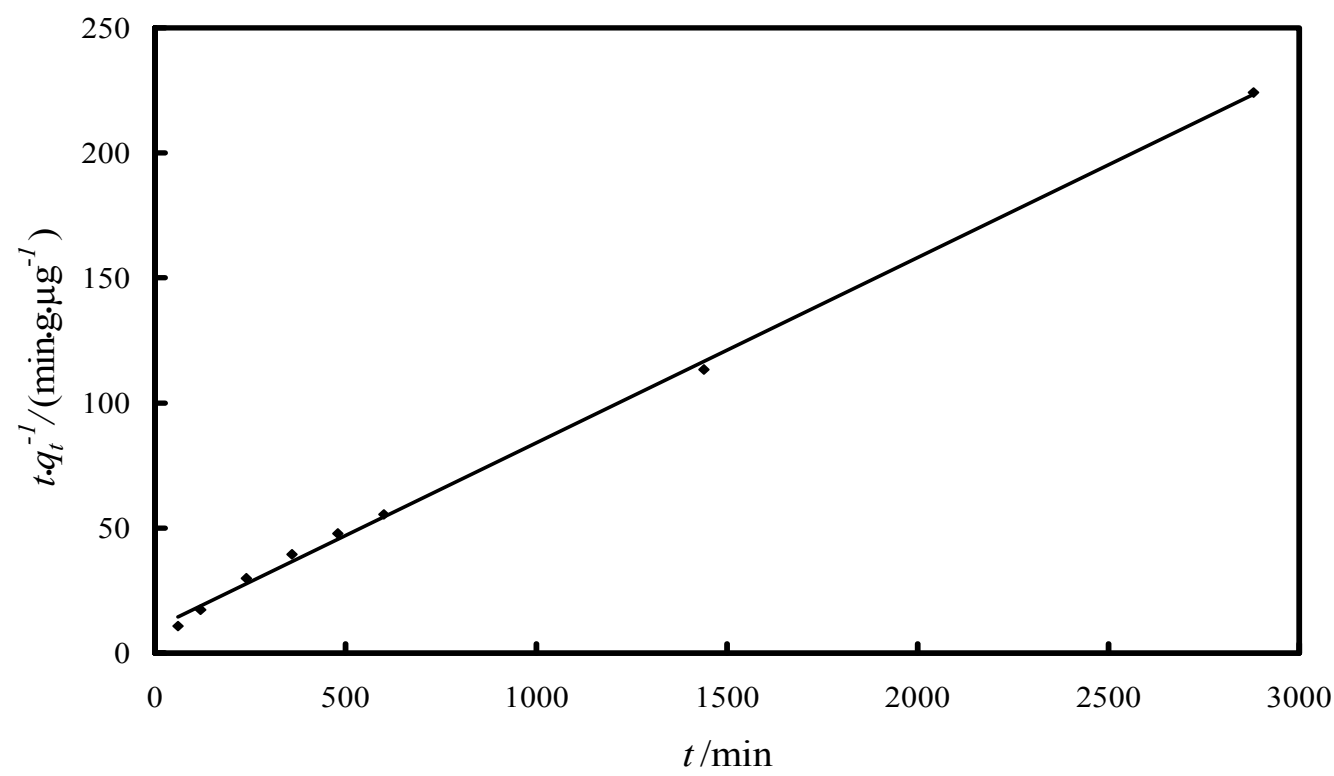


Intra-particle diffusion is an important phenomenon for sorption processes in porous materials. The adsorption of $\mathrm{As}(\mathrm{V})$ ions onto the Fe-XAD8-DEHPA may be controlled via external film diffusion at earlier stages and later by the particle diffusion. The possibility of intra-particle diffusion resistance was identified by using the following Weber-Morris intra-particle diffusion model $[6,7,9]$ :

$$
q_{t}=k_{d i f} \cdot t^{1 / 2}+C
$$

where $k_{\text {dif }}$ is the intra-particle diffusion rate constant $\left(\mu \mathrm{g} \cdot \mathrm{g}^{-1} \cdot \mathrm{min}^{-1 / 2}\right)$ and $C$ is the intercept. The values of $q_{t}$ versus $t^{1 / 2}$ and the rate constant $k_{\text {dif }}$ are directly evaluated from the slope of the regression line (Figure 7).

Figure 7. The Weber-Morris plot for intra-particle diffusion of the $\mathrm{As}(\mathrm{V})$ adsorption kinetic data on Fe-XAD8-DEHPA resin.

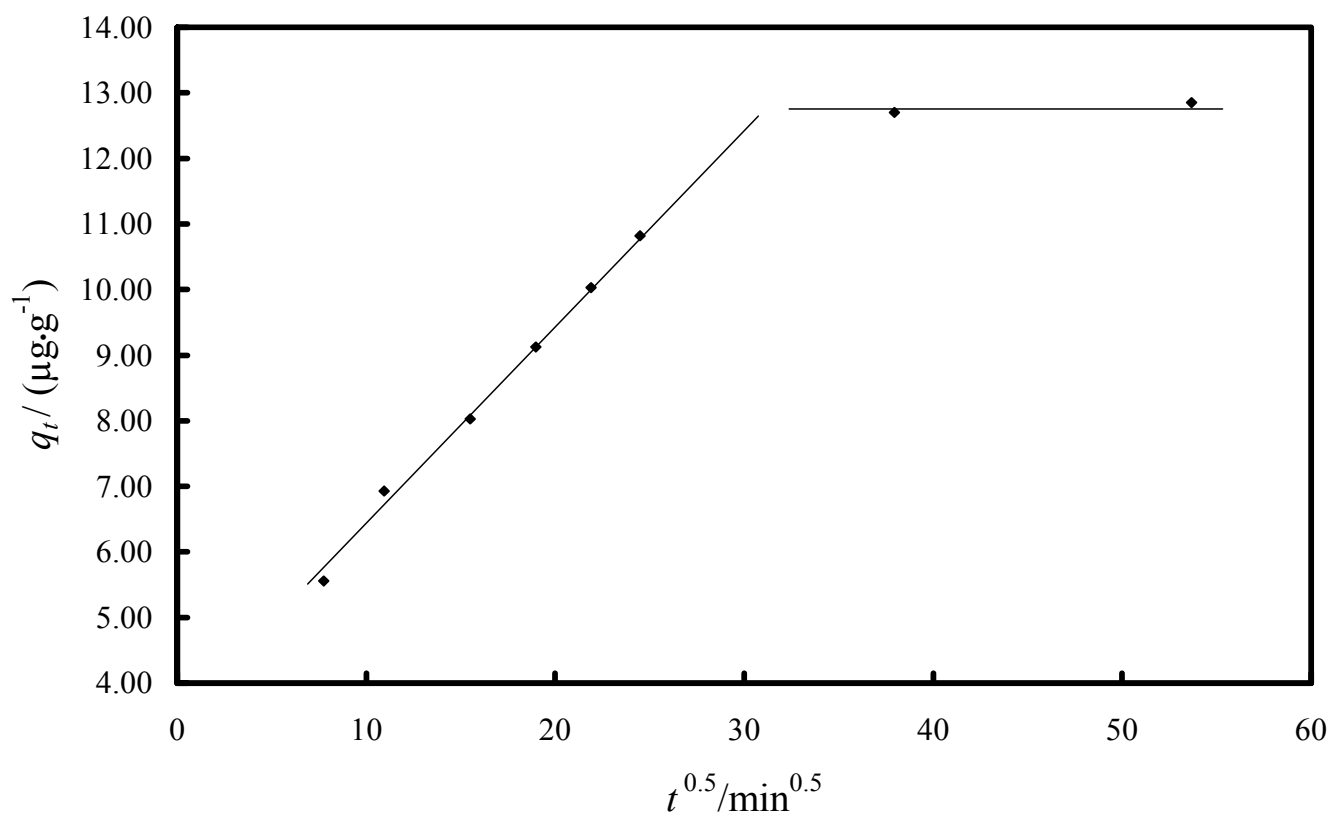

The application of the different kinetic models unveiled some interesting features regarding the mechanism and rate-controlling step in the overall sorption process. The values of the constants, together with the regression coefficients $\left(\mathrm{R}^{2}\right)$ obtained in all cases are summarized in Table 1 .

A poor regression of the pseudo-first-order equation infers that this model does not adequately describe the present adsorption process. Further, there is a great difference between the $q_{e}$ values obtained experimentally and the values obtained directly from the kinetic plot (Figure 5). At the same time, the correlation coefficient for the linear plot of the pseudo-second-order kinetic plot is excellent, greater than 0.99 . The $q_{e}$ values experimentally obtained shows excellent agreement with the value calculated from the kinetic plot. This shows that the kinetic of As(V) removal by Fe-XAD8-DEHPA can be well described by a pseudo-second-order expression. 
Table 1. Kinetic parameters for As(V) adsorption onto Fe-XAD8-DEHPA resin.

\begin{tabular}{cc}
\hline Model/Parameter & Value \\
\hline Pseudo-first-order model & \\
$k_{1} / \mathrm{min}^{-1}$ & 0.0014 \\
$\mathrm{R}^{2}$ & 0.9158 \\
$q_{e}($ experimental $) /\left(\mu \mathrm{g} \cdot \mathrm{g}^{-1}\right)$ & 13 \\
$q_{e}(\mathrm{kinetic} \mathrm{plot}) /\left(\mu \mathrm{g} \cdot \mathrm{g}^{-1}\right)$ & 6.13 \\
\hline Pseudo-second-order model & \\
$k_{2} /\left(\mathrm{g} \cdot \mu \mathrm{g}^{-1} \cdot \mathrm{min}^{-1}\right)$ & $5.45 \times 10^{-4}$ \\
$\mathrm{R}^{2}$ & 0.9957 \\
$q_{e}(\mathrm{experimental}) /\left(\mu \mathrm{g} \cdot \mathrm{g}^{-1}\right)$ & 13 \\
$q_{e}(\mathrm{kinetic} \mathrm{plot}) /\left(\mu \mathrm{g} \cdot \mathrm{g}^{-1}\right)$ & 13.5 \\
\hline Intra-particle diffusion model & \\
$k_{\text {dif }} /\left(\mu \mathrm{g} \cdot \mathrm{g}^{-1} \cdot \mathrm{min}^{-1 / 2}\right)$ & 0.3049 \\
\hline
\end{tabular}

In order to obtain some information regarding which is the rate-limiting step (boundary layer diffusion or intra-particle (pore) diffusion of solute towards the solid surface) of the arsenic adsorption process onto Fe-XAD8-DEHPA resin, the Weber-Morris intraparticle diffusion model was studied. The straight line which passes through origin obtained from the plot of $q_{t}$ against square root of time shows that the rate limiting step is the intraparticle diffusion [38,39]. The deviation of the plot from the line indicates the rate-limiting step should be boundary layer (film) diffusion controlled. The plot of $q_{t}$ versus $t^{0.5}$ in Figure 7 shows that the dependence is not linear for the duration of entire reaction. The line does not pass through the origin, and thus, intra particle diffusion cannot be the rate-limiting step in the sorption process. The plot shows two straight sections, suggesting two different types of sorption mechanisms at the beginning and at the end of the process. The first linear section indicates initial rapid uptake due to film diffusion and consequent external surface coverage by the sorbate. The second linear section suggests the transportation of sorbate inside the sorbent particles [38,39]. This suggests that the $\mathrm{As}(\mathrm{V})$ removal by Fe-XAD8-DEHPA is a complex process.

\subsubsection{Study of the Adsorption Isotherm}

The adsorption isotherm of $\mathrm{As}(\mathrm{V})$ is presented in Figure 8. At high equilibrium concentrations, the adsorption capacity approaches a constant value. This value represents the experimentally determined maximum adsorption capacity of As(V) onto Fe-XAD8-DEHPA $\left(q_{m} \exp >20.2 \mu \mathrm{g} \cdot \mathrm{g}^{-1}\right)$.

Langmuir and Freundlich isotherm studies were conducted in order to investigate the maximum adsorption capacity of Fe-XAD8-DEHPA resin towards As(V) [40]. The relation between the amounts of adsorbate adsorbed by the adsorbent can be expressed by the linearized Langmuir adsorption isotherm as:

$$
\frac{C_{e}}{q_{e}}=\frac{1}{K_{L} \cdot q_{m}}+\frac{C_{e}}{q_{m}}
$$

and the Freundlich isotherm as: 


$$
\ln q_{e}=\ln K_{F}+\frac{1}{n} \cdot \ln C_{e}
$$

where $q_{e}$ is the amount of adsorbate adsorbed per unit of the adsorbent $\left(\mu \mathrm{g} \cdot \mathrm{g}^{-1}\right), K_{L}$ the adsorption constant related to the enthalpy of adsorption $\left(\mathrm{L} \cdot \mu \mathrm{g}^{-1}\right), C_{e}$ the equilibrium concentration of $\operatorname{As}(\mathrm{V})$ $\left(\mu \mathrm{g} \cdot \mathrm{L}^{-1}\right), q_{m}$ the maximum adsorption capacity $\left(\mu \mathrm{g} \cdot \mathrm{g}^{-1}\right)$, and $n$ and $K_{F}$ are the constants depending upon the nature of the adsorbate and adsorbent where $n$ represents the adsorption intensity and $K_{F}$ represents the adsorption capacity $\left(\mu \mathrm{g} \cdot \mathrm{g}^{-1}\right)$. A linear Langmuir isotherm was drawn by plotting $C_{e} \cdot q_{e}{ }^{-1}$ versus $C_{e}$ (Figure 9), while Freundlich isotherm for the adsorption was drawn by plotting $\ln q_{e}$ versus $\ln C_{e}$ (Figure 10). The calculated parameters, as well as the correlation coefficients $\left(\mathrm{R}^{2}\right)$ for $\operatorname{As}(\mathrm{V})$ removal through adsorption onto Fe-XAD8-DEHPA are presented in Table 2.

Figure 8. Adsorption isotherm of As(V) ions onto Fe-XAD8-DEHPA resins; $T=298 \pm 1 \mathrm{~K}$; $\mathrm{pH}=9 \pm 0.1 ; C_{0}=$ range: 10 to $300 \mu \mathrm{g} \cdot \mathrm{L}^{-1} ; m=0.1 \pm 0.0001 \mathrm{~g} ; V=25 \pm 0.1 \mathrm{~mL} ; t=24 \mathrm{~h}$.

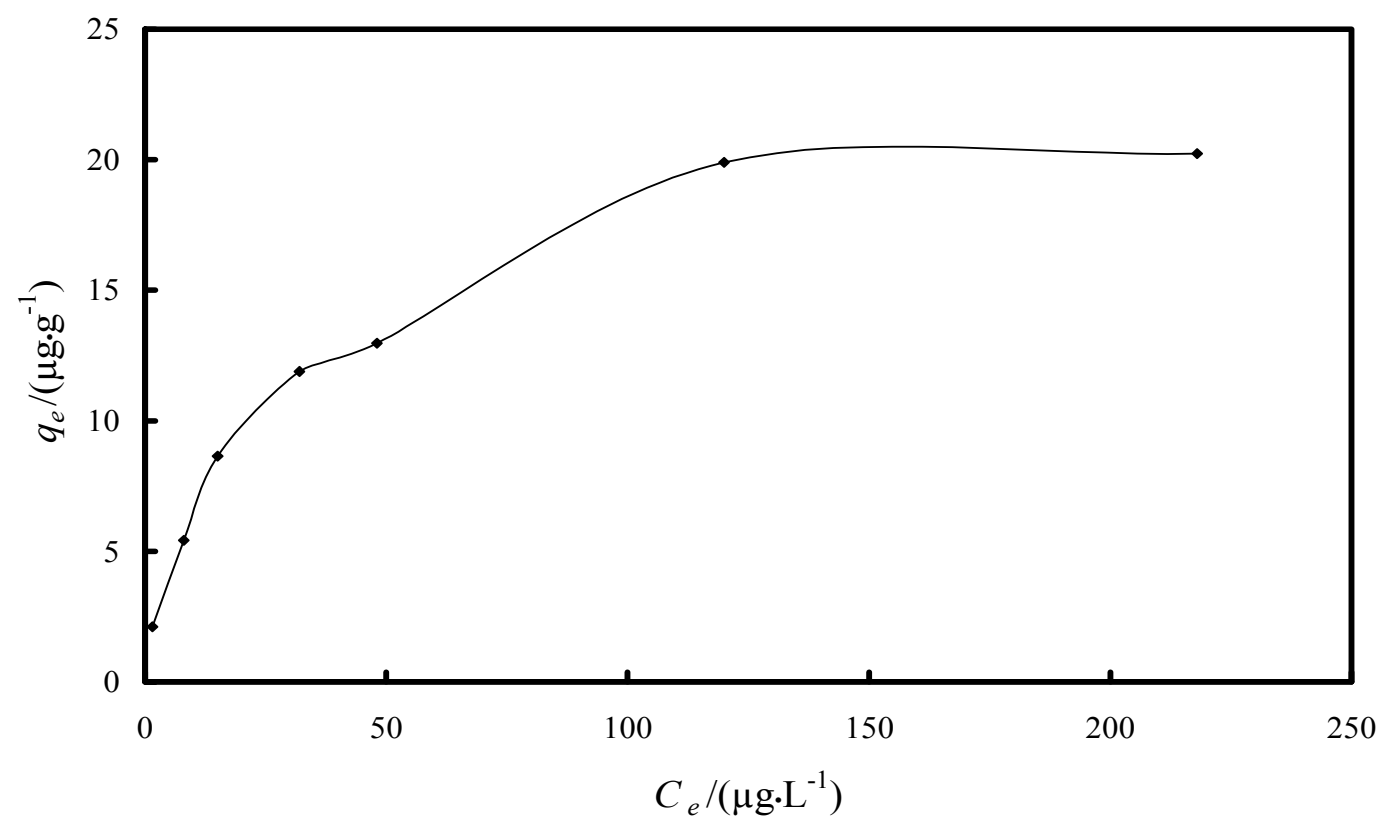

Figure 9. Langmuir isotherm model for As(V) adsorption onto Fe-XAD8-DEHPA resin.

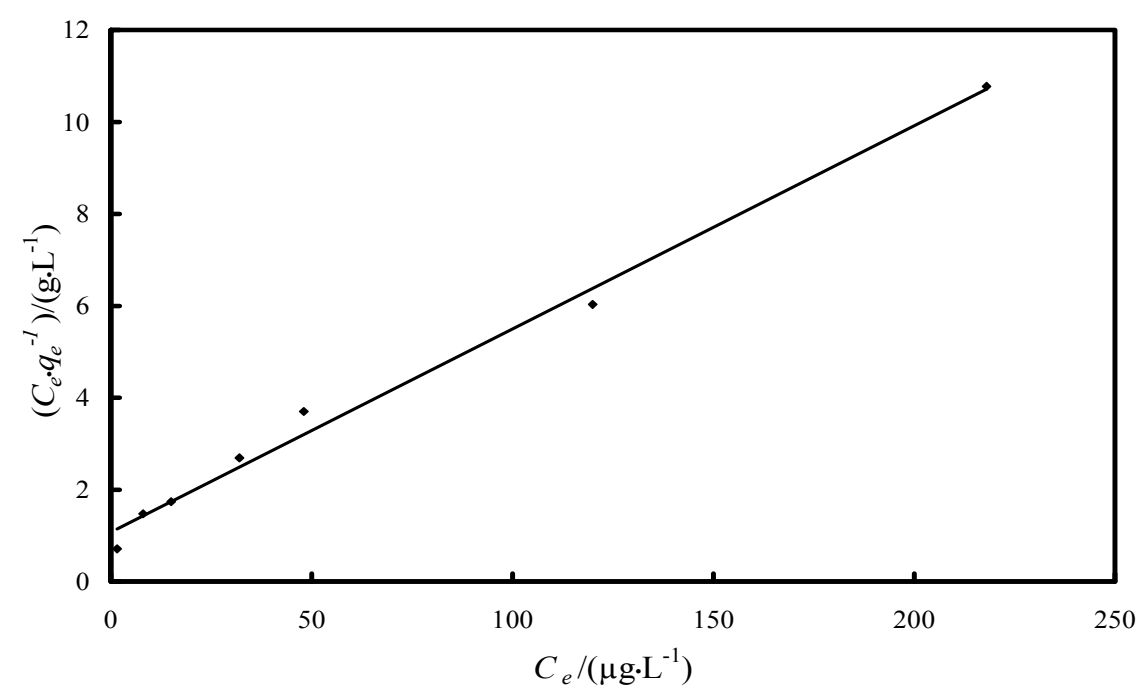


Figure 10. Freundlich isotherm model for As(V) adsorption onto Fe-XAD8-DEHPA resin.

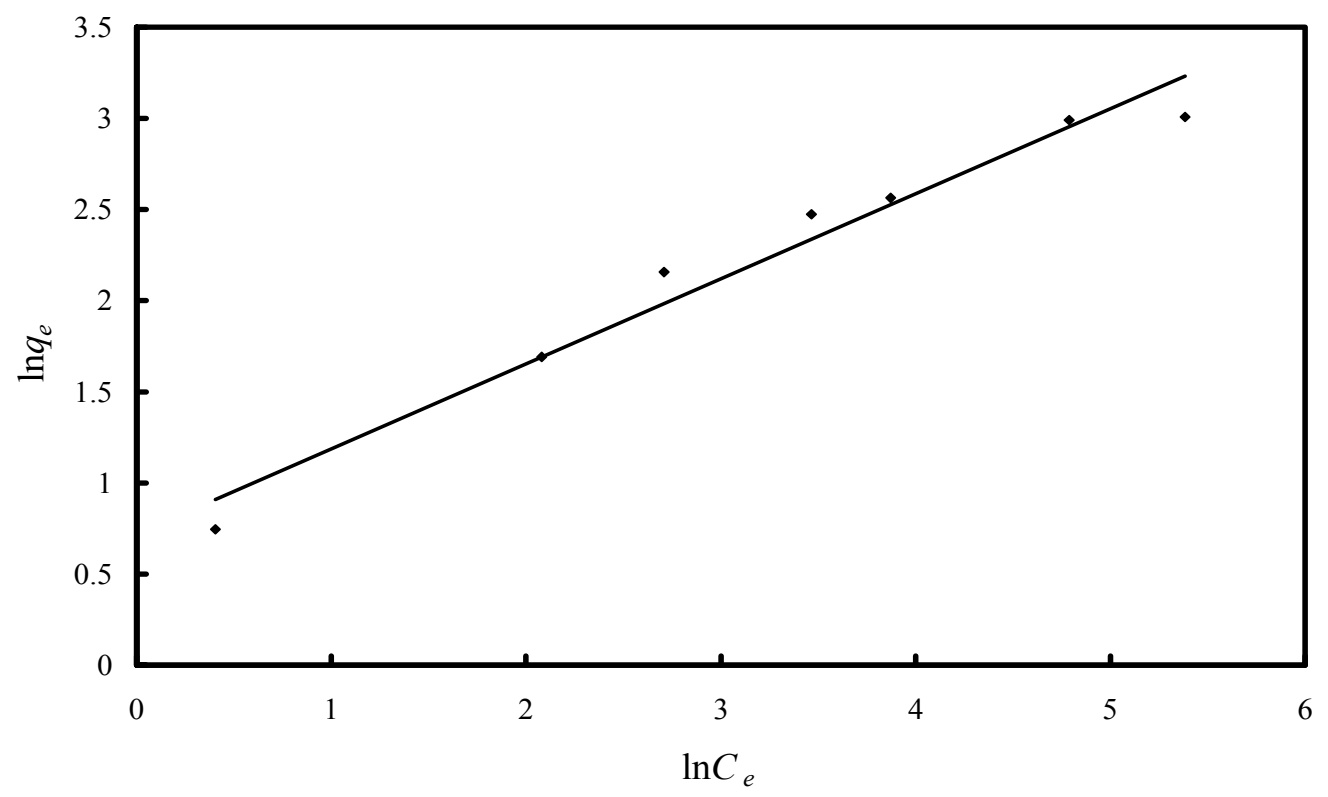

Table 2. Parameters of Freundlich, Langmuir and D-R isotherms for $\mathrm{As}(\mathrm{V})$ adsorption onto Fe-XAD8-DEHPA resin.

\begin{tabular}{cc}
\hline Isotherm/Parameter & Value \\
\hline Langmuir isotherm & \\
$K_{L} /\left(\mathrm{L} \cdot \mu \mathrm{g}^{-1}\right)$ & 0.041 \\
$q_{m} /\left(\mu \mathrm{g} \cdot \mathrm{g}^{-1}\right)$ & 22.6 \\
$\mathrm{R}^{2}$ & 0.9918 \\
\hline Freundlich isotherm & \\
$K_{F} /\left(\mu \mathrm{g} \cdot \mathrm{g}^{-1}\right)$ & 2.055 \\
$1 / n$ & 0.4664 \\
$\mathrm{R}^{2}$ & 0.9667 \\
\hline$D-R$ isotherm & \\
$k /\left(\mathrm{mol}^{2} \cdot \mathrm{kJ}^{-2}\right)$ & 0.0096 \\
$q_{m} /\left(\mu \mathrm{g} \cdot \mathrm{g}^{-1}\right)$ & 24.16 \\
$\mathrm{R}^{2}$ & 0.9921 \\
\hline
\end{tabular}

The Freundlich plot has a lower correlation coefficient than the Langmuir plot. This suggests that the use of the Freundlich isotherm is limited. The Langmuir model effectively describes the equilibrium sorption data (Figure 9); the linear plot has a good correlation coefficient $(>0.99)$ and the maximum adsorption capacity is close to that determined experimentally. The isotherm describes the sorption process for the entire studied concentration range. The maximum adsorption capacity, developed by the studied adsorbent in the removal process of arsenic from water, was compared with other adsorption capacities developed by other materials loaded with iron ions presented in literature (Table 3). 
Table 3. Maximum adsorption capacities develop by various adsorbent loaded with iron ions in the removal process of arsenic from water.

\begin{tabular}{ccc}
\hline Adsorbent & $\boldsymbol{q}_{\boldsymbol{m}} \boldsymbol{\mu} \mathbf{\mu g} \cdot \mathbf{g}^{-\mathbf{1}}$ & References \\
\hline Fe-XAD8-DEHPA & 22.6 & Present work \\
Fe-XAD7-DEHPA & 17.6 & {$[18]$} \\
Fe-IR-120(Na)-DEHPA & 21.8 & {$[41]$} \\
Alginate bead (doped and coated with iron ions & 14 & {$[42]$} \\
Iron oxide coated sand & 8 & {$[43]$} \\
Iron oxide coated sand-2 & 18 & {$[44]$} \\
\hline
\end{tabular}

It can be notice that the present adsorbent developed a higher efficiency in the removal process of $\mathrm{As}(\mathrm{V})$ from aqueous solutions compared with other iron loaded materials present in the literature. The studied adsorbent can be used with success for arsenic removal from waters containing trace concentrations, the most often situation for drinking waters.

However, neither Langmuir nor Freundlich isotherms provide information about the adsorption mechanism. In order to assess the type of adsorption process, the Dubinin-Radushkevich (D-R) isotherm was also employed [45]. This can be expressed as:

$$
\ln q_{e}=\ln q_{m}-k \cdot \varepsilon^{2}
$$

where $\varepsilon$ (Polanyi potential) is given as:

$$
\varepsilon=R \cdot T \cdot \ln \left(1+\frac{1}{C_{e}}\right)
$$

In the above expression, $q_{e}$ is the amount of $\mathrm{As}(\mathrm{V})$ adsorbed $\left(\mathrm{mg} \cdot \mathrm{g}^{-1}\right)$ at equilibrium per unit weight of adsorbent, $q_{m}$ the maximum adsorption capacity $\left(\mathrm{mg} \cdot \mathrm{g}^{-1}\right), C_{e}$ the equilibrium concentration of $\mathrm{As}(\mathrm{V})$ in the solution (ppm), $k$ the constant related to adsorption energy $\left(\mathrm{mol}^{2} \cdot \mathrm{kJ}^{-2}\right), \mathrm{R}$ the universal gas constant $\left(\mathrm{kJ} \cdot \mathrm{mol}^{-1} \cdot \mathrm{K}^{-1}\right)$ and $T$ is the temperature $(\mathrm{K})$. The $\mathrm{D}-\mathrm{R}$ isotherm was drawn by plotting $\ln q_{e}$ against $\varepsilon^{2}$ (Figure 11). $q_{m}$ and $k$ where calculated from the slop and intercept of the graph and the obtained values are presented in Table 2 .

Figure 11. D-R isotherm model for As(V) adsorption onto Fe-XAD8-DEHPA resin.

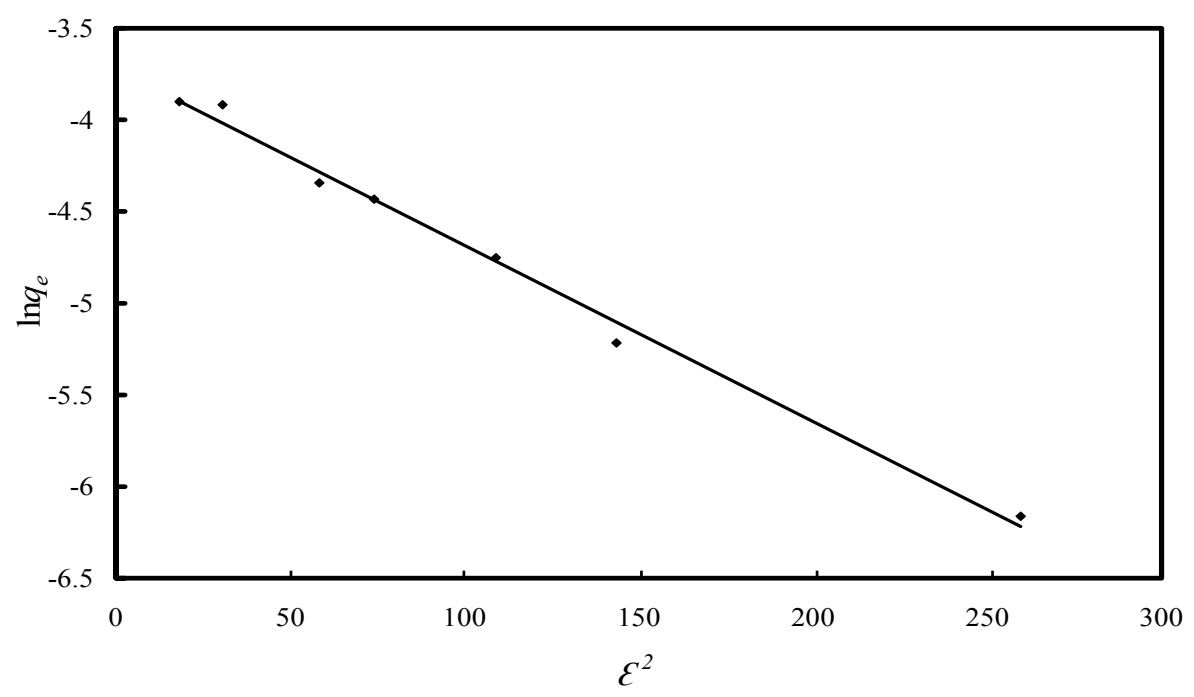


The D-R plot has a good correlation coefficient $(>0.99)$. The monomolecular adsorption capacity $q_{m}$ for Fe-XAD8-DEHPA in the removal process of $\mathrm{As}(\mathrm{V})$ from aqueous solutions is $24.16 \mu \mathrm{g} \cdot \mathrm{g}^{-1}$; a value which is very close to that determined experimentally. The mean free energy of adsorption $(E)$, defined as free energy change when one mole of ion is transferred from infinity in solution to the surface of the solid, was calculated from the $k$ value using the following formula $[22,45]$ :

$$
E=\frac{1}{\sqrt{2 k}}
$$

The magnitude of $E$ is a indicator which shows if the adsorption is physical in nature $\left(E \leq 8 \mathrm{~kJ} \cdot \mathrm{mol}^{-1}\right)$ or chemical $\left(E\right.$ is in the range of $\left.8-16 \mathrm{~kJ} \cdot \mathrm{mol}^{-1}\right)[22,40]$. The value of $E$ found in this study was $7.2 \mathrm{~kJ} \cdot \mathrm{mol}^{-1}$, suggesting a physical adsorption (due to weak van der Waals forces).

In order to predict the adsorption efficiency of the adsorption process and to assess if the process is favourable or unfavourable for the Langmuir type adsorption, the isotherm shape can be classified by a term $R_{L}$, a dimensionless constant separation factor, which is defined by the following equation:

$$
R_{L}=\frac{1}{1+K_{L} \cdot C_{0}}
$$

where $C_{0}$ is the initial concentration of $\mathrm{As}(\mathrm{V})(\mathrm{ppb})$ and $K_{L}$ is the Langmuir isotherm constant. The value of $R_{L}$ indicates the shape of the isotherm to be unfavourable, $R_{L}>1$; linear, $R_{L}=1$; favourable $0<R_{L}<1$; and irreversible, $R_{L}=0[5-7,12,36]$. In our case $R_{L}$ values were found to be between 0 and 1 for all the concentration of $\mathrm{As}(\mathrm{V})$ ions showing that the adsorption is favourable. Furthermore, the standard Gibbs free energy changes $\left(\Delta G^{\circ}\right)$ for the adsorption process can be calculated by using the following equation:

$$
\ln \left(\frac{1}{K_{L}}\right)=\frac{\Delta G^{0}}{R T}
$$

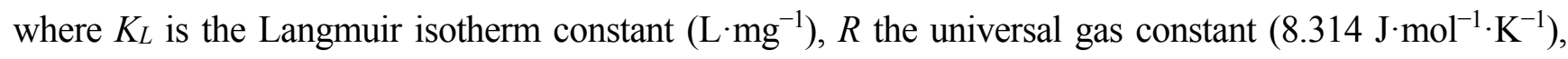
and $T$ is the absolute temperature $(K)$. The calculated $\Delta G^{\circ}$ value is $-9.2 \mathrm{~kJ} \cdot \mathrm{mol}^{-1}$. The negative $\Delta G^{\circ}$ value indicates that the adsorption is spontaneous.

\subsection{Fixed-Bed Column Study}

The efficiency of the treatment technique depends on the concentration and species of arsenic as well as on the presence of other constituents in the water. A fixed bed column study was conducted with real arsenic bearing ground water. The real arsenic-bearing water sample had the composition: $\mathrm{NO}^{3-}: 20 \mathrm{mg} \cdot \mathrm{L}^{-1} ; \mathrm{NO}^{2-}: 0.5 \mathrm{mg} \cdot \mathrm{L}^{-1} ; \mathrm{P}_{2} \mathrm{O}_{5}: 5 \mathrm{mg} \cdot \mathrm{L}^{-1} ; \mathrm{SO}_{4}^{2-}: 10.2 \mathrm{mg} \cdot \mathrm{L}^{-1} ; \mathrm{NH}_{4}^{+}: 6.4 \mathrm{mg} \cdot \mathrm{L}^{-1} ; \mathrm{Fe}^{\mathrm{n}+}$ : $1.8 \mathrm{mg} \cdot \mathrm{L}^{-1} ; \mathrm{Mn}^{2+}: 0.6 \mathrm{mg} \cdot \mathrm{L}^{-1} ; \mathrm{Na}^{+}: 120 \mathrm{mg} \cdot \mathrm{L}^{-1} ; \mathrm{K}^{+}: 1.75 \mathrm{mg} \cdot \mathrm{L}^{-1} ; \mathrm{Ca}^{2+}: 30 \mathrm{mg} \cdot \mathrm{L}^{-1} ; \mathrm{Mg}^{2+}: 18 \mathrm{mg} \cdot \mathrm{L}^{-1}$; $\mathrm{As}^{\mathrm{n}+}: 80 \mu \mathrm{g} \cdot \mathrm{L}^{-1}$.

The breakthrough curve is shown in Figure 12. The breakthrough time obtained was $6 \mathrm{~h}$ and corresponds to $C / C_{0}=0.0375$ (when $3 \mathrm{~L}$ of arsenic-bearing water were treated), while the exhaust time, that corresponds to $C / C_{0}=0.5$ was found to be at $14.6 \mathrm{~h}$ (when $7.3 \mathrm{~L}$ arsenic-bearing water were treated). The fixed bed column was designed by the logit method $[45,46]$. The logit equation can be written as: 


$$
\ln \left[\frac{C}{C_{0}-C}\right]=-\frac{K N X}{v}+K C_{0} t
$$

where $C$ is the solute concentration at any time $t, C_{0}$ the initial solute concentration ( $\left.80 \mathrm{ppb}\right), v$ the approach velocity $(\sim 7.6 \mathrm{~cm} / \mathrm{h}), X$ the bed depth $(5 \mathrm{~cm}), K$ the adsorption rate constant $\left(\mathrm{L} \cdot(\mu \mathrm{g} \cdot \mathrm{h})^{-1}\right)$, and $N$ is the adsorption capacity coefficient $\left(\mu \mathrm{g} \cdot \mathrm{L}^{-1}\right)$. Plot of $\ln \left[C \cdot\left(C_{0}-C\right)\right]$ versus $\mathrm{t}$ is shown in Figure 13. The value of adsorption rate coefficient $(K)$ and adsorption capacity coefficient $(N)$ was obtained as $7.41 /\left(\mathrm{L} \cdot(\mathrm{mg} \cdot \mathrm{h})^{-1}\right)$ and $10.09 /\left(\mathrm{mg} \cdot \mathrm{L}^{-1}\right)$. These values could be used to design the adsorption column.

Figure 12. Breakthrough curve for arsenic using Fe-XAD8-DEHPA.

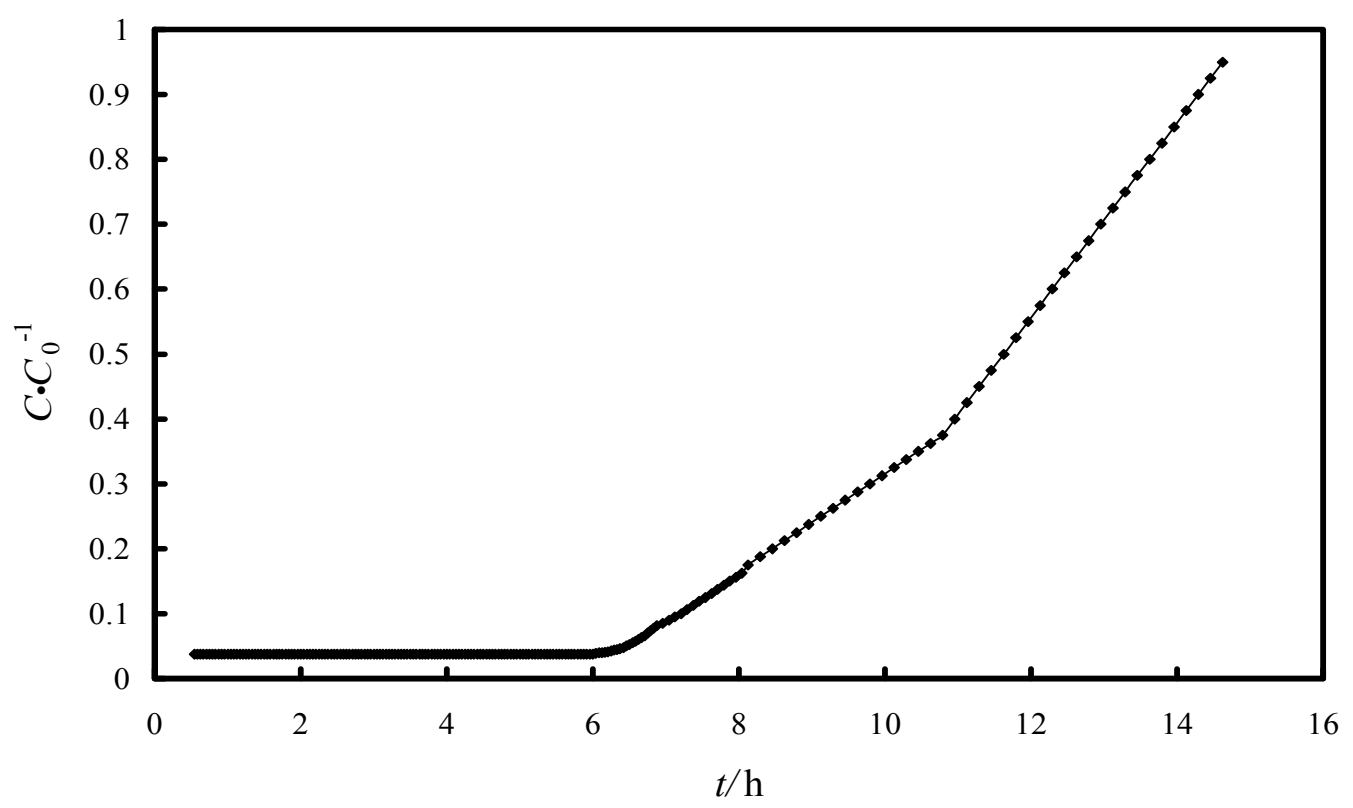

Figure 13. Linearized form of logit model.

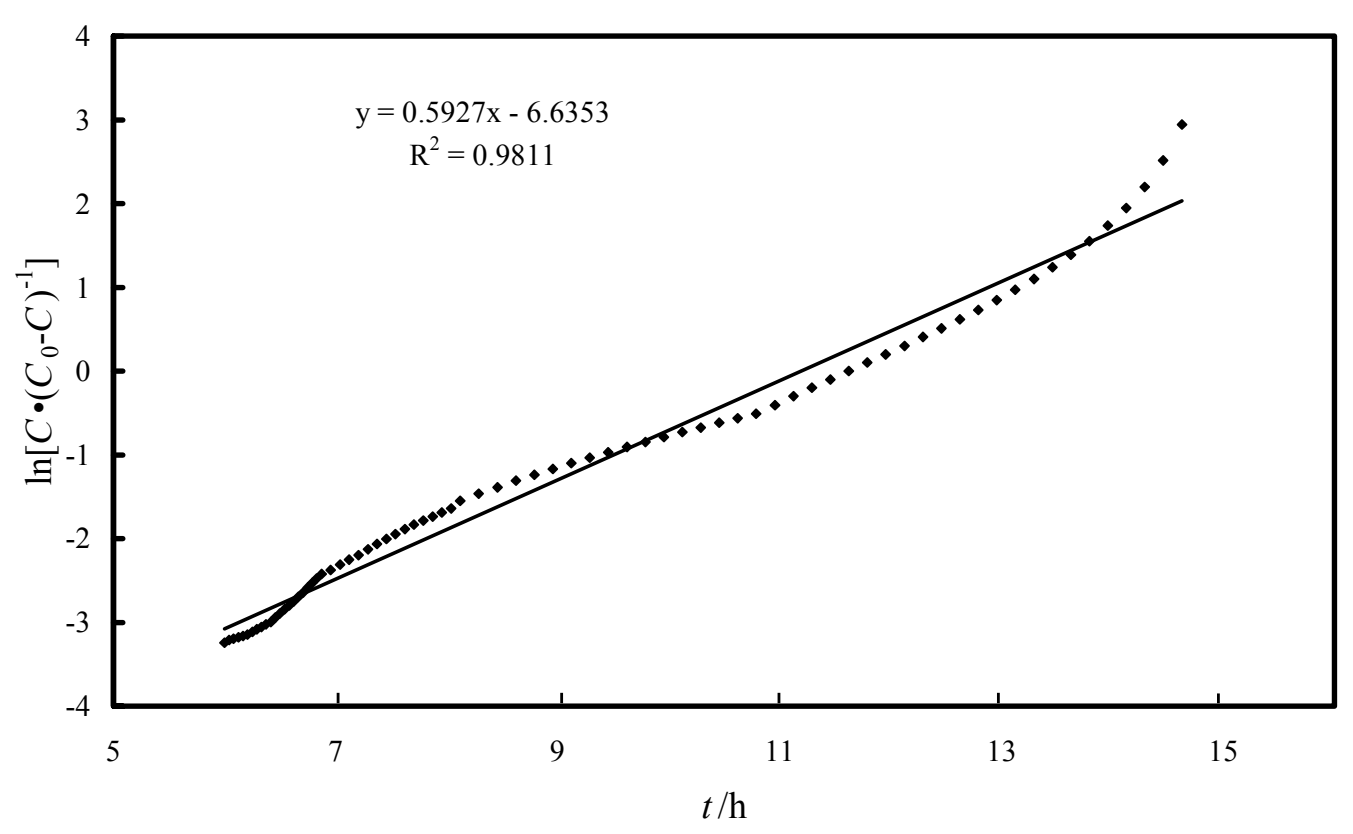




\subsection{Quality Parameters of the Effluent Water}

The quality parameters of the effluent water after column adsorption were also determined. It was observed that beside arsenic, the studied adsorbent could also remove iron and manganese ions from the sample (residual concentrations fell under the AAS limits of detection of $0.01 \mathrm{mg} \cdot \mathrm{L}^{-1}$ for iron and manganese and $0.01 \mu \mathrm{g} \cdot \mathrm{L}^{-1}$ for arsenic). These results are in agreement with other studies where it was observed that the arsenic was quantitatively removed together with iron and manganese ions [47]. The $\mathrm{pH}$ of the effluent water remained almost the same as in the influent water suggesting that no post treatment is necessary. All these indicate that the Fe-XAD8-DEHPA resin could be used as an efficient and practical adsorbent for arsenic removal from underground waters.

\subsection{Desorption Study}

From the standpoints of cost-effectiveness and environmental friendliness; it is highly desirable that the sorbent to be amenable to efficient regeneration and re-use. We found that the regeneration capacity of exhausted Fe-XAD8-DEHPA increased with the increasing concentration of the used regenerant $(\mathrm{HCl}$ or $\mathrm{NaOH})$. The adsorbent could be efficiently regenerated by using a $5 \% \mathrm{HCl}$ solution, but in this case Fe ions loaded onto XAD8-DEHPA resin leached out together with the arsenic ions. Consequently the regenerated resin should in such cases be reloaded with $\mathrm{Fe}(\mathrm{III})$ ions before re-use, which somewhat increases the cost of the adsorption process. For this reason, we consider the $5 \% \mathrm{NaCl}$ solution to be the better regenerant, with the use of which the desorption performance is still $92 \%$.

Even if some authors mentioned that the use of ion-exchange for arsenic removal present a better Environmental Sustainability Assessment compared with the adsorption process [48], the research from this paper showed that the use of Fe-XAD8-DEHPA as adsorbent material in the As(V) removal process presents good efficiency both in batch and fixed-bed column tests, and especially in the treatment process of real underground drinking water, without the applying any extra pre-treatment processes. The adsorbent material can be regenerated and efficiently reused in the adsorption process in this way decreasing the treatment costs. All these results underline the sustainability of arsenic removal through adsorption.

\section{Experimental Section}

\subsection{Adsorbent Preparation}

The Amberlite XAD8 resin (Rohm and Haas Co., Philadelphia, PA, U.S.A.) was impregnated with di(2-ethylhexyl) phosphoric acid (DEHPA) via the dry method. This macro reticular polymeric adsorbent is dimensionally and chemically quite stable and quite insoluble. The impregnation procedure was described elsewhere [18,22]. Scheme 1 shows the possible mechanism of impregnation.

The resulted phosphorylated resin was further loaded with Fe(III) ions. The hydroxyl iron ions after coordination in the aqueous medium with the neutral waters molecules are loaded onto the impregnated resin according to the reaction mechanism described in Scheme 2. 
Scheme 1. The mechanism of XAD8 impregnation with DEHPA.<smiles>[R]OP(=O)(O)O[R]</smiles>

Scheme 2. Loading mechanism of Fe(III) ions onto XAD8-DEHPA resin.

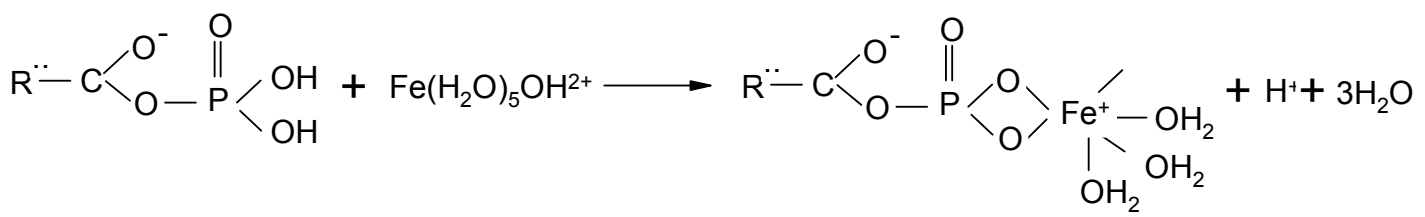

In order to determine the maximum quantity of $\mathrm{Fe}$ (III) ions that can be loaded onto the impregnated resin, the influence of the $\mathrm{Fe}$ (III) ions initial concentration onto the $\mathrm{Fe}$ (III) uptake was investigated. To this end $0.1 \mathrm{~g}$ of resin was suspended in $25 \mathrm{~mL}$ of $\mathrm{Fe}(\mathrm{III})$ ions solutions ( $\mathrm{Fe}\left(\mathrm{NO}_{3}\right)_{3}$ Merck Standard solution) each having a different $\mathrm{Fe}(\mathrm{III})$ concentrations in the range from 10 to $200 \mathrm{mg} \cdot \mathrm{L}^{-1}$ ). The suspensions were let to stand in contact for $24 \mathrm{~h}$ in order to reach the equilibrium. After this contact time the samples were filtrated and the concentration of iron in the clear solutions was determined using a Varian SpectrAA 280 type atomic absorption spectrometer (Varian Australia Pty Ltd., Mulgrave, VIC, Australia) equipped with an air-acetylene flame atomizer. The optimum concentration of the $\mathrm{Fe}(\mathrm{III})$ ions solution for the XAD8-DEHPA resin loading was found to be $100 \mathrm{mg} \cdot \mathrm{L}^{-1}$. A higher quantity of XAD8-DEHPA impregnated resin was equilibrated with a $100 \mathrm{mg} \cdot \mathrm{L}^{-1} \mathrm{Fe}(\mathrm{III})$ ions solution in the $\mathrm{S}: \mathrm{L}$ ratio $\mathrm{S}: \mathrm{L}=0.1: 25$ for $24 \mathrm{~h}$. Fe loaded XAD8-DEHPA resin was separated by vacuum filtration, washed with distilled water until $\mathrm{pH}$ was neutral and dried at $323 \mathrm{~K}$. The obtained Fe-XAD8-DEHPA was submitted to FTIR spectroscopy and EDX analysis in order to establish if the impregnation with DEHPA and the iron loading occurred. The FTIR spectra of KBr-pelletized samples were recorded using a (Prestige-21) FTIR spectrophotometer (Shimadzu Europa GmbH, Duisburg, Germany) in the range of $4000-400 \mathrm{~cm}^{-1}$ with $2 \mathrm{~cm}^{-1}$ resolution and 40 scans were performed. The EDX study was performed using an Inspect S50 scanning electron microscope (FEI, Hillsboro, OR, USA).

\subsection{Batch Experiments for Arsenic Removal}

Due to the fact that in aqueous solution at $\mathrm{pH}$ value of $9 \pm 0.1$ the anionic species of $\mathrm{As}(\mathrm{V})$ $\left[\mathrm{H}_{2} \mathrm{AsO}_{4}{ }^{-}\right.$or $\left.\mathrm{HAsO}_{4}{ }^{2-}\right]$ are the predominant ones $[6,9,11]$, all the experiments were carried out at this $\mathrm{pH}$ value. The $\mathrm{pH}$ of the solutions was adjusted to this value using a $1 \mathrm{M} \mathrm{NaOH}$ solution, thereby keeping the volume variation of the solution to a value as low as possible. The $\mathrm{pH}$ was controlled with MultiMeter MM41 (Crison, Barcelona, Spain) fitted with a glass electrode calibrated by using various buffer solutions. Prior to the equilibrium sorption experiments, a stock solution of arsenic in $0.5 \mathrm{M}$ $\mathrm{HNO}_{3}$ was prepared using an appropriate amount of $\mathrm{H}_{3} \mathrm{AsO}_{4}$ (Merck, Darmstadt, Germany). Other solutions of $\mathrm{As}(\mathrm{V})$ ions were prepared from the stock solution by appropriate dilution. The arsenate adsorption onto the Fe(III) loaded XAD8-DEHPA resin is mainly attributable to the adsorption of monovalent arsenate anions $\mathrm{H}_{2} \mathrm{AsO}_{4}{ }^{-}$. The adsorption of monovalent arsenate may take place by releasing hydroxyl anions or neutral water molecules from the coordination sphere of the Fe(III) ions 
loaded onto the XAD8-DEHPA resin (Scheme 3), similar to the mechanism proposed for other iron or zirconium-based adsorbents [28,31,32,35-46,49-51].

Scheme 3. The mechanism of arsenate adsorption onto Fe-XAD8-DEHPA resin.<smiles>[R]C([O-])OP1(=O)O[P+](O)(O)[P+](O)(O)O1</smiles>

In the first experiment the effect of contact time was studied. The arsenic adsorption performance of the Fe-XAD8-DEHPA the experiments was assessed using $0.1 \mathrm{~g}$ of the adsorbent and $25 \mathrm{~mL}$ of a $100 \mu \mathrm{g} \cdot \mathrm{L}^{-1} \mathrm{As}(\mathrm{V})$ solution. The samples were kept in contact for different times (range: $1-24 \mathrm{~h}$ ) at the room temperature $298 \mathrm{~K}$. After the contact time, the suspensions were filtered and the residual arsenic concentration in the filtrates was determined by hydride generation atomic absorption spectrometry, using a Varian SpectrAA 110 flame atomic absorption spectrometer equipped with a Varian VGA 77 hydride generation system. Similar equilibrium experiments were performed to study the influence of the initial As(V) concentration $\left(10,30,50,80,100,200\right.$ and $\left.300 \mu \mathrm{g} \cdot \mathrm{L}^{-1}\right)$. In each experiment, $0.1 \mathrm{~g}$ of studied material was suspended in $25 \mathrm{~mL}$ of $\mathrm{As}(\mathrm{V})$ solution of different concentration (range: $10-300 \mu \mathrm{g} \cdot \mathrm{L}^{-1}$ ) for $24 \mathrm{~h}$ at the room temperature. After the contact time the filtrate was collected and subjected to arsenic analysis.

The adsorption capacity of the impregnated resin expressed as the metal uptake, $q / \mu \mathrm{g} \cdot \mathrm{g}^{-1}$, can be obtained using the next mass balance expression [36,45,51]:

$$
q_{t}=\frac{\left(C_{0}-C_{t}\right) \cdot V}{m}
$$

where $C_{0}$ and $C_{t}$ are the concentrations of $\mathrm{As}(\mathrm{V})$ ions $\left(\mu \mathrm{g} \cdot \mathrm{L}^{-1}\right)$ in the solution initially $(t=0)$ and after a time $t$ ( $\mathrm{min}$ ), respectively, $V$ is the volume of the solution and $m$ is the mass of adsorbent. The experimental results are given as an average of five sets of data obtained under identical working conditions.

\subsection{Fixed-Bed Column Study for Arsenic Removal}

The arsenic adsorption in dynamic regime was made on a fixed-bed column packed with Fe-XAD8-DEHPA resin. The installation was composed from: a glass column with an i.d. of $2 \mathrm{~cm}$ and $30 \mathrm{~cm}$ length, where the impregnated resin layer was of $5 \mathrm{~cm}$, a vessel which contain the arsenic-containing water from where it was pumped with the help of a peristaltic pump in the column in the down-flow mode with a volumetric flow rate of $8.33 \mathrm{~mL} \cdot \mathrm{min}^{-1}\left(0.796 \mathrm{~m}^{3} \cdot \mathrm{m}^{-2} \cdot \mathrm{h}^{-1}\right)$. At the bottom of the column the samples were collected at certain time intervals and were analyzed for their arsenic concentrations.

\subsection{Desorption Studies}

Desorption of arsenic from the exhausted Fe-XAD8-DEHPA resin was carried out using $1 \mathrm{~g}$ of exhausted adsorbent, $25 \mathrm{~mL}$ of $\mathrm{HCl}$ solution and $\mathrm{NaCl}$ solutions of various concentrations $(1 \%, 3 \%$, 
and $5 \%$ ) by magnetic agitation for $2 \mathrm{~h}$ at the room temperatures. After the contact time the filtrate was collected for arsenic analysis.

All chemicals employed in the experiments were A.R. grade and used without further purification. Distilled water was used throughout.

\section{Conclusions}

In the present study we have shown that Fe-XAD8-DEHPA adsorbent can be efficiently used for the removal of arsenic from natural underground waters. The adsorption mechanism appears to follows a pseudo-second-order kinetics. The presence of intraparticle diffusion showed that adsorption process is complex and involves multiple mechanisms. The adsorption was also evaluated according to the Langmuir, Freundlich and D-R isotherm models, obtaining a maximum adsorption capacity from the Langmuir isotherm of $22.6 \mu \mathrm{g} \mathrm{As}(\mathrm{V}) / \mathrm{g}$ of Fe-XAD8-DEHPA resin. The values obtained from the fixed-bed column test could be used to design an adsorption column. In addition, on the column study was demonstrated that a residual concentration of arsenic lower than the maximum limit allowed by the World Health Organization of $10 \mu \mathrm{g} / \mathrm{L}$ can be reached. Compared with other iron loaded adsorbent material mentioned in the literature the proposed one developed a highest adsorption capacity, it can be used with success for arsenic removal from waters containing trace concentrations, the most often situation for drinking waters.

\section{Acknowledgments}

This work was partially supported by the strategic grant POSDRU/89/1.5/S/57649, Project ID 57649 (PERFORM-ERA), co-financed by the European Social Fund-Investing in People, within the Sectoral Operational Programme Human Resources Development 2007-2013.

\section{Author Contributions}

C.M.D. initiated and supervised the POSDRU project, this publication being part of this project. C.M.D. and P.N. conceived and designed the impregnation process and wrote the paper. P.N. analyzed and interpreted the characterization of the obtained adsorbent material. A.N. and M.C. performed the adsorption experiments, arsenic analyses and wrote the paper. L.L. fitted and interpreted the experimental data and wrote and edited the manuscript. All authors read and approved the final manuscript.

\section{Conflicts of Interest}

The authors declare no conflicts of interest.

\section{References}

1. Cotruvo, J.; Fawell, J.K.; Giddings, M.; Jackson, P.; Magara, Y.; Festo Ngowy, A.V.; Ohanian, E. Arsenic in Drinking Water; World Health Organization: Geneva, Switzerland, 2011.

2. Ramesh, A.; Hasegawa, H.; Maki, T.; Ueda, K. Adsorption of inorganic and organic arsenic from aqueous solutions by polymeric A1/Fe modified montmorillonite. Sep. Purif. Technol. 2007, 56, 90-100. 
3. Guo, H.; Stuben, D.; Berner, Z. Arsenic removal from water using natural iron mineral-quartz sand columns. Sci. Total Environ. 2007, 377, 142-151.

4. Kundu, S.; Gupta, A.K. Adsorptive removal of As(III) from aqueous solution using iron oxide coated cement (IOCC): Evaluation of kinetic, equilibrium and thermodynamic models. Sep. Purif. Technol. 2006, 51, 165-172.

5. Borah, D.; Satokawa, S.; Kato, S.; Kojima, T. Surface-modified carbon black for As(V) removal. J. Colloid Interface Sci. 2008, 319, 53-62.

6. Borah, D.; Satokawa, S.; Kato, S.; Kojima, T. Sorption of As(V) from aqueous solution using acid modified carbon black. J. Hazard. Mater. 2009, 162, 1269-1277.

7. Negrea, A.; Lupa, L.; Ciopec, M.; Lazau, R.; Muntean, C.; Negrea, P. Adsorption of As(III) ions onto iron-containing waste sludge. Adsorpt. Sci. Technol. 2010, 28, 467-484.

8. Goswami, R.; Deb, P.; Thakur, R.; Sarma, K.P.; Bsumalick, A. Removal of As(III) from aqueous solution using functionalized ultrafine iron oxide nanoparticles. Sep. Sci. Technol. 2011, 46, $1017-1022$.

9. Gupta, K.; Ghosh, U.C. Arsenic removal using hydrous nanostructure iron(III)-titanium(IV) binary mixed oxide from aqueous solution. J. Hazard. Mater. 2009, 161, 884-892.

10. Hlavay, J.; Polyak, K. Determination of surface properties of iron hydroxide coated alumina adsorbent prepared from drinking water. J. Colloid Interface Sci. 2005, 284, 71-77.

11. Banerjee, K.; Amy, G.L.; Prevost, M.; Nour, S.; Jekel, M.; Gallagher, P.M.; Blumenschein, C.D. Kinetic and thermodynamic aspects of adsorption of arsenic onto granular ferric hydroxide (GFH). Water Res. 2008, 42, 3371-3378.

12. Oke, I.A.; Olarinoye N.O.; Adewusi, S.R.A. Adsorption kinetics for arsenic removal from aqueous solutions by untreated powdered eggshell. Adsorption 2008, 14, 73-83.

13. Juang, R.S. Preparation, properties and sorption behaviour of Impregnated resins containing acidic organophosphorus extractants. Proc. Natl. Sci. Counc. ROC 1999, 23, 353-364.

14. Shao, W.; Li, X.; Cao, Q.; Luo, F.; Li, J.; Du, Y. Adsorption of arsenate and arsenite anions from aqueous medium by using metal(III)-loaded Amberlite resins. Hydrometallurgy 2008, 91, 138-143.

15. Zhu, X.; Jyo, A. Removal of arsenic(V) by zirconium(IV)-loaded phosphoric acid chelating resin. Sep. Sci. Technol. 2001, 36, 3175-3189.

16. Saha, B.; Gill, R.J.; Bailey, D.G.; Kabay, N.; Arda, M. Sorption of Cr(VI) from aqueous solution by Amberlite XAD-7 resin impregnated with ALiquat 336. React. Funct. Polym. 2004, 60, 223-244.

17. Belkhouche, N.E.; Didi, M.A. Extraction of Bi(III) from nitrate medium by D2EHPA impregnated onto Amberlite XAD-1180. Hydrometallurgy 2010, 103, 60-67.

18. Negrea, A.; Ciopec, M.; Lupa, L.; Davidescu, C.M.; Popa, A.; Ilia, G.; Negrea, P. Removal of $\mathrm{As}(\mathrm{V})$ by $\mathrm{Fe}(\mathrm{III})$ loaded XAD7 impregnated resin containing di(2-ethylhexyl) phosphoric acid (DEHPA): Equilibrium, Kinetic and Thermodynamic modelling studies. J. Chem. Eng. Data 2011, 56, 3830-3838.

19. Ciopec, M.; Negrea, A.; Davidescu, C.M.; Negrea, P.; Muntean, C.; Popa, A. Use of Di-(2-Ethylhexyl)-Phosphoric Acid (DEHPA) Impregnated XAD-8 Copolymer Resin for the Separation of Metal Ions from Water. Chem. Bull. 2010, 55, 127-131. 
20. Suzuki, T.M.; Bomani, J.O.; Matsunga, H.; Yokoyama, T. Preparation of porous resin loaded with crystalline hydrous zirconium oxide and its application to the removal of arsenic. React. Funct. Polym. 2000, 43, 165-172.

21. Haron, M.J.; Shiah, L.L.; Wan Yunus, W.M.Z. Sorption of arsenic *V( by titanium oxide loaded poly(hydroxamic acid) resin. Malays. J. Anal. Sci. 2006, 10, 261-268.

22. Benamor, M.; Bouariche, Z.; Belaid, T.; Draa, M.T. Kinetic studies on cadmium ions by Amberlite XAD7 impregnated resin containing di(2-ethylhexyl) phosphoric acid as extractant. Sep. Purif. Technol. 2008, 59, 74-84.

23. Mendoza, R.N.; Medina, I.S.; Vera, A.; Rodriguez, M.A. Study of the sorption of Cr(III) with XAD-2 resin impregnated with di-(2,4,4-trimethylpentyl)phosphinic acid (Cyanex 272). Solvent Extr. Ion Exch. 2000, 18, 319-343.

24. Muraviev, D.; Ghantous, L.; Valiente, M. Stabilization of solvent impregnated resin capacities by different techniques. React. Funct. Polym. 1998, 38, 259-268.

25. Mukherjee, A.; Sengupta, M.K.; Hossain, M.A.; Ahamed, S.; Das, B.; Nayak, B.; Lodh, D.; Rahman, M.M.; Chakraborti, D. Arsenic contamination in groundwater: A global perspective with emphasis on the Asian scenario. J. Health Popul. Nutr. 2006, 24, 142-163.

26. Negrea, A.; Muntean, C.; Ciopec, M.; Lupa, L.; Negrea, P. Removal of arsenic from underground water to obtain drinking water. Chem. Bull. 2009, 54, 82-84.

27. Awual, M.R.; Shenashen, M.A.; Yaita, T.; Shiwaku, H.; Jyo, A. Efficient arsenic(V) removal from water by ligand exchange fibrous adsorbent. Water Res. 2012, 46, 5541-5550.

28. Awual, M.R.; El-Safty, S.A.; Jyo, A. Removal of trace arsenic (V) and phosphate from water by a highly selective ligand exchange adsorbent. J. Environ. Sci. 2011, 23, 1947-1954.

29. Awual M.R.; Urata, S.; Jyo, A.; Tamada, M.; Katakai, A. Arsenate removal from water by a weak-base anion exchange fibrous adsorbent. Water Res. 2008, 42, 689-696.

30. Awual, M.R.; Hossain, A.; Shenashen, M.A.; Yaita, T.; Suzuki, S.; Jyo, A. Evaluating of arsenic(V) removal from water by weak-base anion exchange adsorbent. Environ. Sci. Pollut. Res. 2013, 20, 421-430.

31. Awual, M.R.; Jyo, A. Rapid column-mode removal of arsenate from water by crosslinked poly(allylamine) resin. Water Res. 2009, 43, 1229-1236.

32. Chanda, M.; O’Driscoll, K.F.; Rempel, G.L. Ligand exchange sorption of arsenate and arsenite anions by chelating resins in ferric ion form: II. Iminodiacetic chelating resin chelex 100 . React. Polym. 1988, 8, 85-95.

33. Greenleaf, J.E.; Lin, J.C.; Sengupta, A.K. Two novel applications of ion exchange fibers: Arsenic removal and chemical-free softening of hard water. Environ. Prog. 2006, 25, 300-311.

34. German, M.; Seingheng, H.; SenGupta, A.K. Mitigating arsenic crisis in the developing world: Role of robust, reusable and selective hybrid anion exchange (HAIX). Sci. Total Environ. 2014, 488-489, 547-553.

35. Etmannski, T.R.; Darton, R.C. A methodology for the sustainability assessment of arsenic mitigation technology for drinking water. Sci. Total Environ. 2014, 488, 509-515.

36. Streat, M.; Hellgardt, K.; Newton, N.L.R. Hydrous ferric oxide as an adsorbent in water treatment: Part 2. Adsorption studies. Process Saf. Environ. 2008, 86, 11-20. 
37. An, B.; Steinwinder, T.R.; Zhao, D. Selective removal of arsenate from drinking water using a polymeric ligand exchanger. Water Res. 2005, 39, 4993-5004.

38. Chen, Y.N.; Chai, L.Y.; Shu, Y.D. Study of arsenic (V) adsorption on bone char from aqueous solution. J. Hazard. Mater. 2008, 160, 168-172.

39. Weber, W.J.; Moris, J.C. Kinetics of adsorption on carbon from solution. J. Sanit. Eng. Div. Am. Soc. Civ. Eng. 1963, 89, 31-60.

40. Mendoza-Barron, J.; Jacobo-Azuara, A.; Levya-Ramos, R.; Berber-Mendoza, S.; Guerrero-Coronado, R.M.; Fuentes-Rubio, L.; Martinez-Rosales, J.M. Adsorption of arsenic (V) from a water solution onto a surfactant-modified zeolite. Adsorption 2011, 17, 489-496.

41. Ciopec, M.; Negrea, A.; Lupa, L.; Davidescu, C.; Negrea, P.; Sfarloaga, P. Performance evaluation of the Fe-IR-120(Na)-DEHPA impregnated resin in the removal process of As(V) from aqueous solution. J. Mater. Sci. Eng. B 2011, 1, 421-432.

42. Zouboulis, A.J.; Kalsoyiannis, I.A. Arsenic removal using iron oxide, loaded aliginate beads. Ind. Eng. Chem. Res. 2002, 41, 6149-6155.

43. Thirunavukkarasu, O.S.; Viraraghavan, T.; Subramanian, K.S.; Tanjore, S. Organic arsenic removal from drinking water. Urban Water 2002, 4, 415-421.

44. Viraghavan, T.; Thirunavukkarasu, O.S.; Subramanian, K.S. Removal of arsenic in drkingin water by iron oxide coated sand and ferrihydrite-batch studies. Water Qual. Res. J. Can. 2001, 36, 55-70.

45. Maji, S.K.; Pal, A.; Pal, T. Arsenic removal from real-life ground water by adsorption on laterite soil. J. Hazard. Mater. 2008, 151, 811-820.

46. Adak, A.; Bandyopadhyay, M.; Pal, A. Removal of anionic surfactant form wastewater by alumina: A case study. Colloid Surf. A: Physicochem. Eng. Asp. 2005, 254, 165-171.

47. Noubactep, C.; Care, S.; Blatkeu, B.D.; Nanseu-Njiki, C.P. Enhancing the sustainability of household $\mathrm{Fe}^{0} /$ sand filters by using bimetallics and $\mathrm{MnO}_{2}$. CLEAN Soil Air Water 2012, 40, 100-109.

48. Dominguez-Ramos, A.; Chavan, K.; Garcia, V.; Jimeno, G.; Albo, J.; Marathe, K.V.; Yadav, G.D.; Irabien, A. Arsenic removal from natural waters by adsorption or ion exchange: An environmental sustainability assessement. Ind. Eng. Chem. Res. 2014, doi:10.1021/ie4044345.

49. Mohan, D.; Pittman, C.U. Arsenic removal from water/wastewater using adsorbents -A critical review. J. Hazard. Mater. 2007, 142, 1-53.

50. Rau, I.; Gonzalo, A.; Valiente, M. Arsenic (V) adsorption by immobilized iron mediation. Modeling of the adsorption process and influence of interfering anions. React. Funct. Polym. 2003, 54, 85-94.

51. Ohe, K.; Tagai, Y.; Nakamura, S.; Oshima, T.; Baba, Y. Adsorption behaviour of arsenic(III) and arsenic(V) using magnetite. J. Chem. Eng. Jpn. 2005, 38, 671-676.

Sample Availability: Samples of the compounds Fe-XAD8-DEHPA are available from the authors.

(C) 2014 by the authors; licensee MDPI, Basel, Switzerland. This article is an open access article distributed under the terms and conditions of the Creative Commons Attribution license (http://creativecommons.org/licenses/by/4.0/). 